containing 46 transistors on six different nanotubes.

Although the method would be difficult to scale up with current materials, the authors say that the units could be used to explore the potential limits of integrated circuits based on carbon nanotubes.

Nano Lett. http://doi.org/svv(2014)

\section{METABOLISM}

\section{A longer life with less pain}

Mice that lack a class of pain receptors have a longer lifespan and a more youthful metabolism than normal mice.

Previous work had shown

that, compared with control animals, mice missing TRPV1 pain receptors were less sensitive to pain and were less likely to become obese when fed a calorie-rich diet. Andrew Dillin of the University of California, Berkeley, and his colleagues have now found that such mice also live $12-16 \%$ longer than control mice.

The mutant mice make less of a molecule called CGRP in the pancreas. This, in turn, boosts insulin secretion, improving the control of blood-sugar levels. Furthermore, treating aged mice with an inhibitor of CGRP made their metabolic profiles look more like those of younger animals.

Cell 157, 1023-1036(2014)

\section{ECOLOGY}

\section{Dancing bees reveal better land}

Researchers have decoded the honeybee's dance to determine which types of land the insects prefer.

Honeybees do a 'waggle dance' (pictured) to tell their nestmates the best places to forage for nectar and pollen. Margaret Couvillon and her colleagues at the University of Sussex in Brighton, UK, observed foraging honeybees (Apis mellifera) from three colonies for two years. By analysing more than 5,000 waggle dances, the team found that the bees preferred tracts of land with greater stewardship, and a nature reserve with abundant wildflowers, to land sown with organic seed mixes and frequently mowed.

The authors suggest that bees could be used as indicators for improving environmental management.

Curr. Biol. http://doi.org/sv9 (2014)

\section{CLIMATE CHANGE}

\section{Soot drives Greenland melting}

Forest fires in the Northern Hemisphere have helped to spur record surface melting of ice in Greenland.

Kaitlin Keegan of Dartmouth College in Hanover, New

Hampshire, and her colleagues analysed six shallow ice cores from different areas of Greenland's interior. They found that both the record melting in 2012 and the last similarly widespread melting event in 1889 were caused by a combination of unusually warm air temperatures and increased heat absorption by snow laden with soot from distant forest fires.

Average summer temperatures and the frequency of forest fires in the Northern Hemisphere are projected to rise - and so, by the end of the century, widespread surface melting in Greenland might happen in almost any year, the authors say. Proc. Natl Acad. Sci. USA http://doi.org/svz (2014)

\section{ANIMAL BEHAVIOUR}

\section{Wild mice run for fun on wheels}

Exercise wheels are popular among laboratory mice, but it seems that wild mice - and even frogs and shrews - also
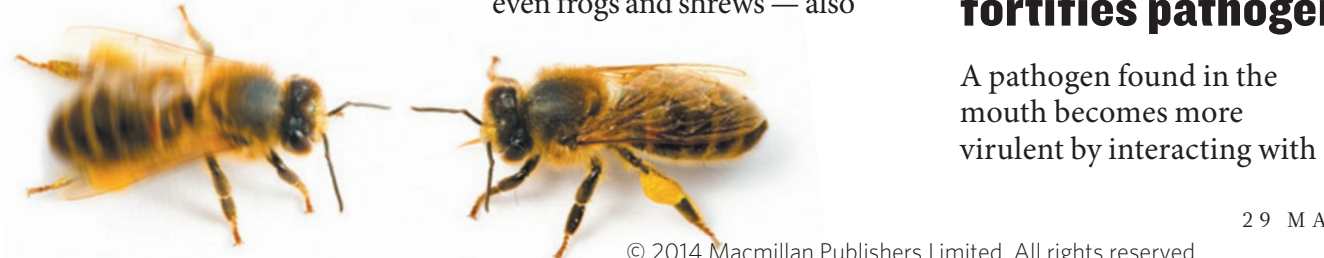

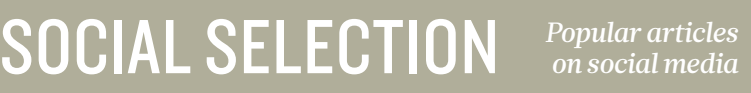

\title{
Price of knowledge prompts reflection
}

Researchers on social media have been hashing out the big question of just how much scientific information is out there, with many discussing a recent article on accessing that knowledge. Using data gleaned from Google Scholar and Microsoft Academic Search, researchers at Pennsylvania State University in University Park estimated that more than 114 million English-language scholarly works - journal papers, dissertations, master's theses, books and technical reports - exist as resources online. But much of the bounty can be had only for a price. Pollution scientist Andrew Singer of the NERC Centre for Ecology and Hydrology in Wallingford, UK, noted on Twitter that "only" $24 \%$ of the works were open-access. "That's quite a low number," he says. "It's disappointing to see how resistant we are to change." Khabsa, M. \& Giles, C. L. PLoS ONE 9, e93949 (2014)

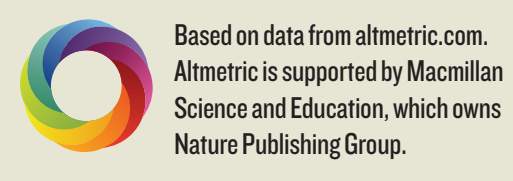

DNATURE.COM

For more on popular papers: go.nature.com/alvaol use them to go for a jog.

Some have argued that wheel-running is not a natural behaviour and could even be a result of neurosis. Johanna Meijer and Yuri Robbers at Leiden University Medical Centre in the Netherlands set up exercise wheels at two sites where wild mice live, and collected video for more than three years. They found that the median running speed of wild mice was lower than that of their captive counterparts, but wild mice reached higher maximum speeds. The animals were initially attracted to the equipment by food rewards, but continued to use the wheels when food was absent.

The study suggests that wheel-running is a voluntary behaviour, the authors say. Proc. R. Soc. B 281, 20140210 (2014)

\section{Fight and flight fortifies pathogen}

A pathogen found in the virulent by interacting with an innocuous oral bacterium. The harmless species Streptococcus gordonii produces hydrogen peroxide as an antimicrobial, but the bacterium also makes lactate that benefits the pathogen Aggregatibacter actinomycetemcomitans, which causes gum disease. Marvin Whiteley of the University of Texas at Austin and his colleagues discovered that the pathogen either fights peroxide with a detoxifying enzyme, or escapes the site where the antimicrobial is produced.

These 'fight-and-flight' responses help the pathogen to move far enough away to be protected from the peroxide, but also to remain close enough to continue feeding on lactate. This results in an infection that is more severe than one caused by the pathogen alone, say the researchers.

Proc. Natl Acad. Sci. USA http://doi.org/sv4 (2014)

\section{$\rightarrow$ NATURE.COM}

For the latest research published by Naturevisit:

www.nature.com/latestresearch 